\title{
National Perinatal Association Annual Conference 2020 - Multidisciplinary Care in the 4th Trimester
}

Viveka Prakash-Zawisza, MD, Jerry Ballas, MD, MPH

The National Perinatal Association (NPA) is an interdisciplinary organization that strives to be a leading voice for perinatal care in the United States. Our diverse membership is comprised of healthcare providers, parents \& caregivers, educators, and service providers, all driven by their desire to give voice to and support babies and families at risk across the country.

Members of the NPA write a regular peer-reviewed column in Neonatology Today.

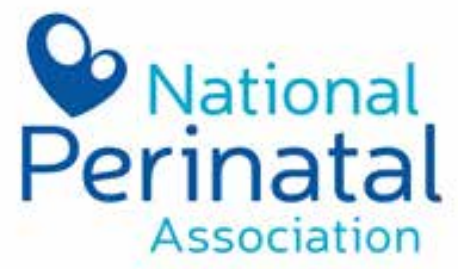

Educate. Advocate. Integrate.

\section{"This year the chosen theme focused on the 4th Trimester and the various areas of vulnerability for parents and infants during this time, as well as the resources available for support."}

As a national group of perinatal advocates, providers, and parents, the National Perinatal Association strives to select a theme for its annual conference that reflects cur-

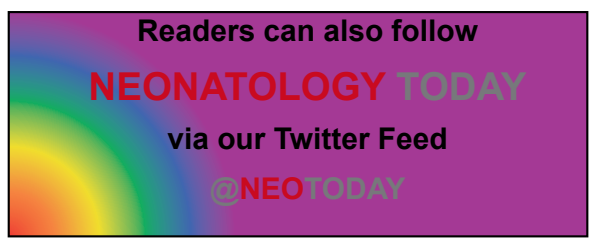

rent trends and best practices that most impact the perinatal community. This year the chosen theme focused on the $4^{\text {th }}$ Trimester and the various areas of vulnerability for parents and infants during this time, as well as the resources available for support.

The $4^{\text {th }}$ Trimester is defined as the period of time following birth up to 12 weeks postpartum. This time period is so named as it reflects the particular features of the early postpartum weeks as being a continuation of the pregnancy in many ways. Human babies are born without the ability to move independently or feed themselves, making them entirely reliant on a caregiver to meet their basic needs. As such, in many ways, they are still in a fetal state despite being outside the uterus. In parallel, the new mother is physically healing from childbirth, figuring out how to breastfeed, and learning all about her new baby's cues. It is a time of intense critical bonding for both infant and parent, an establishing of psychological, emotional, and physical connection and attachment. Given how special and fleeting this time is, the need to protect a mother's ability to stay with her newborn without interruption and to receive whatever support necessary in case of physical or mental health needs is paramount. Therefore, this year's conference topics were related to strengthening state and federal parental leave policies, health equity, perinatal mood and anxiety disorders, substance use disorders, and special considerations for NICU parents. The undeniable impact of the Covid-19 pandemic on the perinatal landscape was also woven throughout the conference.

\section{A meeting like no other:}

While this may seem like a typical superlative, an organization may use to boost its conference profile, this year's NPA conference was literally like no other annual meeting held in its 40-year history. While necessary in light of the Covid-19 pandemic, the pivot to a virtual platform was uncharted territory for NPA. Aside from the technological and logistical hurdles we had to overcome, there was the genuine concern of capturing the same interest and anticipation most speakers, attendees, and sponsors reserve for in-person events of this kind. As spring turned to summer, and it became increasingly apparent that our postponed meeting would become a virtual meeting, our Conference Committee internally adopted the mantra "We Got This," took a collective breath, and then made the announcement to all our speakers, presenters, sponsors, and attendees.

\section{"As spring turned to summer, and it became increasingly apparent that our postponed meeting would become a virtual meeting, our Conference Committee internally adopted the mantra "We Got This," took a collective} breath, and then made the announcement to all our speakers, presenters, sponsors, and attendees."

To our surprise at the time, the announcement barely made any waves. Speakers stayed committed, sponsors stuck with us, poster presenters pivoted to video format, and attendance increased as the conference approached. What would become abundantly clear, especially now looking back on such an amazing turn of events, is that the passion and expertise of our presenters, the growing interest in the $4^{\text {th }}$ Trimester, and the feeling of fellowship NPA meetings are known for would overcome the barriers put in place by Covid-19.

\section{Day One: Caring for the Family Unit:}

There could not have been a better way to start such an impactful meeting than having Jenné Johns and Shanté Nixon team up to discuss their unique perspectives on starting their families. From Jenné's intense NICU experience and ongoing mission to educate others to Shanté's journey 


\section{Welcome}
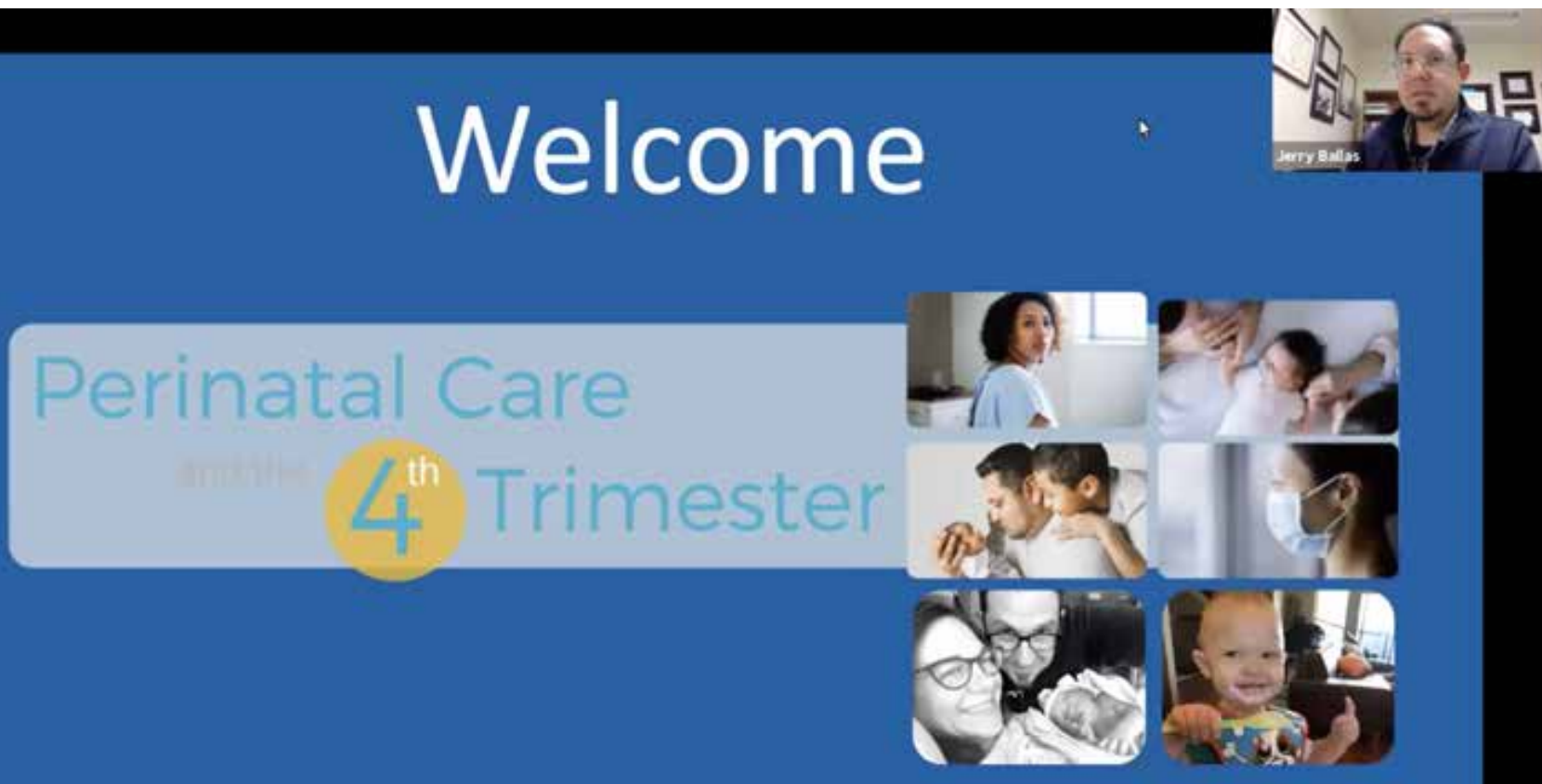

P National Perinatal

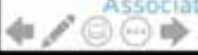
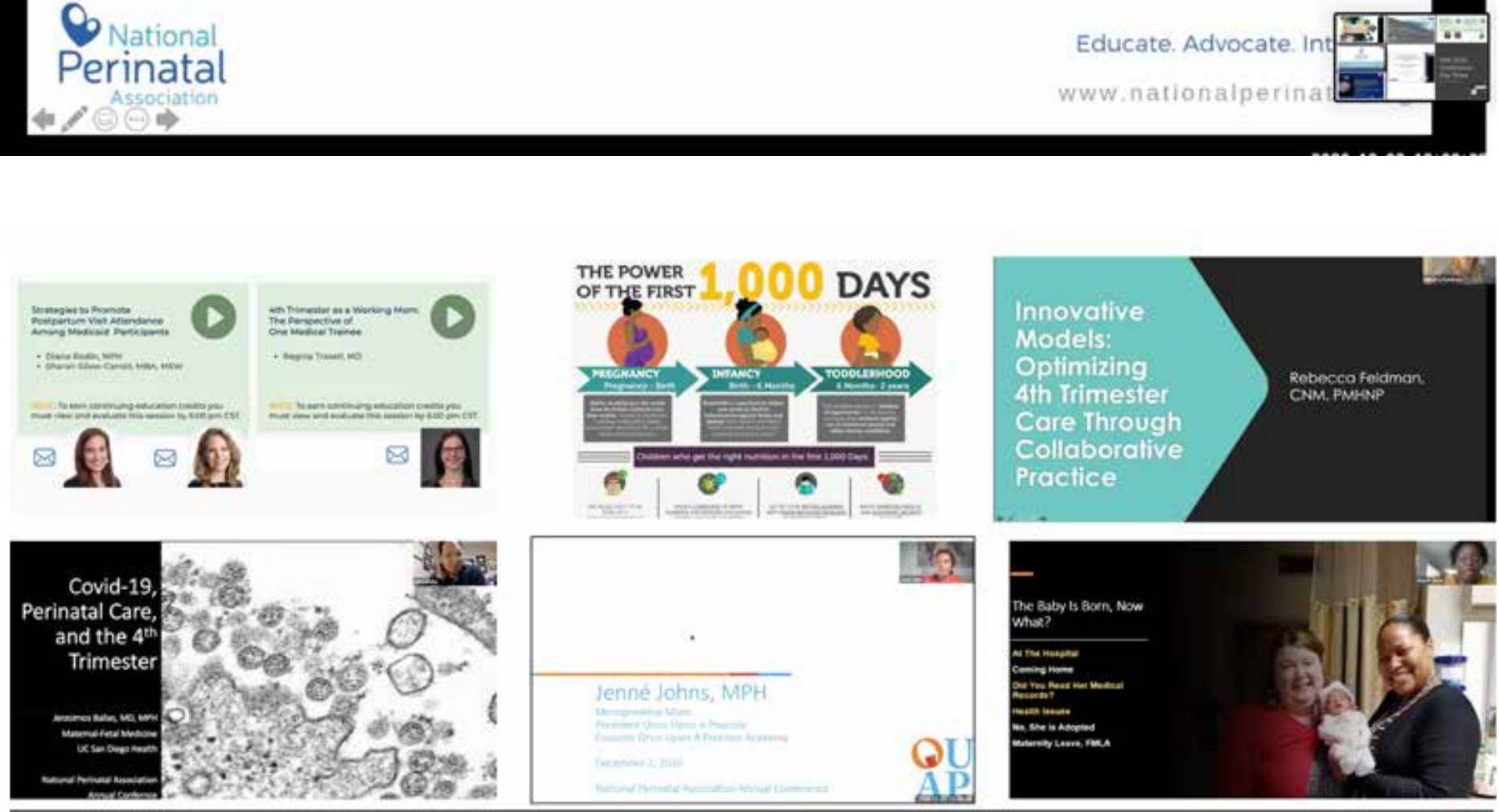

NPA 2020 Conference: Day One 


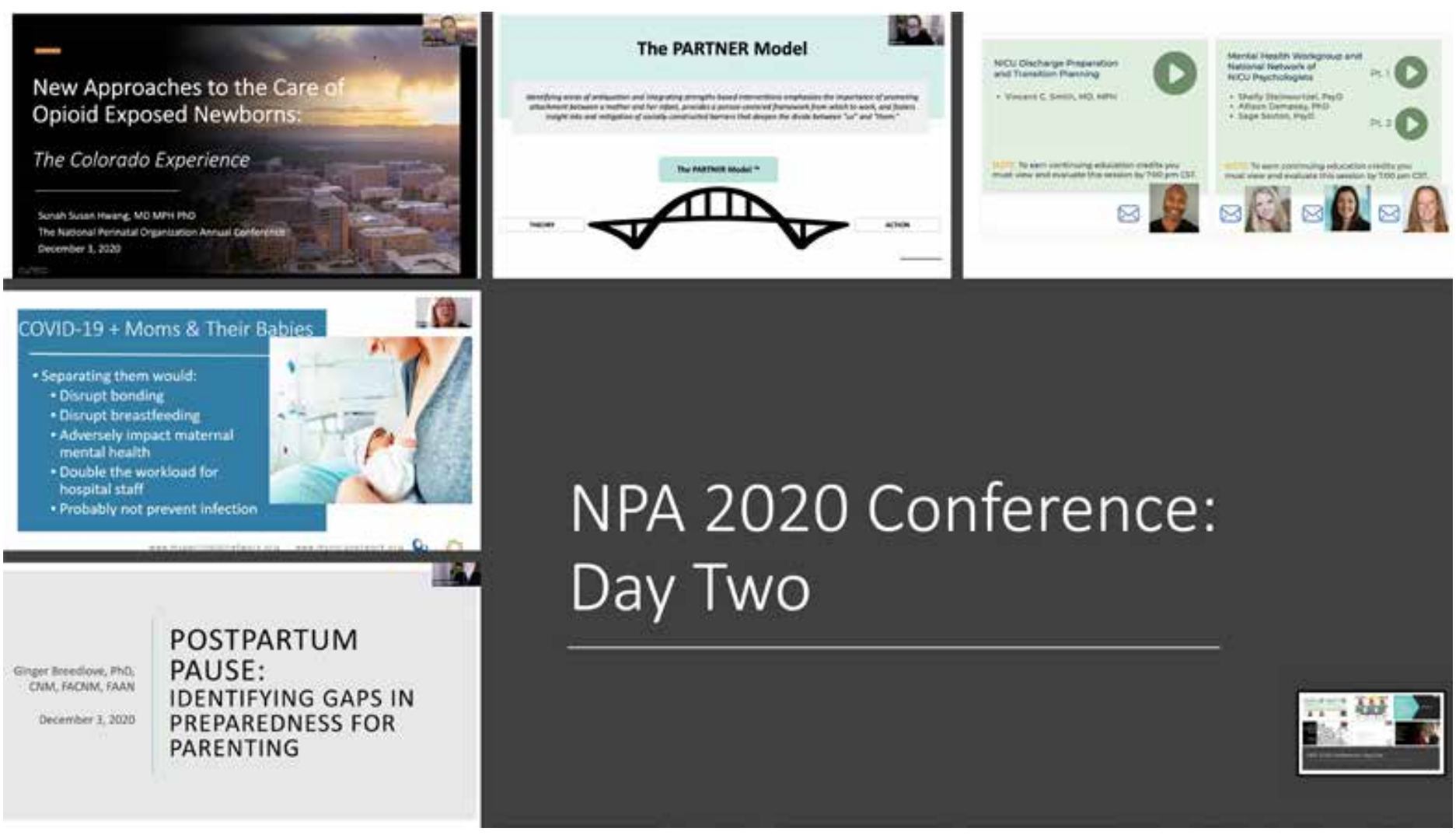

to motherhood through adoption, the ambitious goal of defining the full spectrum of perinatal care and the $4^{\text {th }}$ Trimester was perfectly set. Blythe Thomas from 1,000 Days then followed up by piecing together many aspects of Jenné and Shanté's stories to drive home the importance of substantive family medical leave policies and provide updates and resources to help advocate for change at the legislative level. We then heard from Rebecca Feldman, CNM, about the power of collaborative, perinatal group programs aimed at optimizing mental health treatment and reducing barriers to care in the $4^{\text {th }}$ Trimester. Finally, Jerry Ballas provided an overview, a current snapshot of the effects of Covid-19 on perinatal care, and some of the innovations that have emerged from the pandemic, including a resurgence in telehealth and traumainformed care. In addition to these live sessions, pre-recorded breakout sessions were available to attendees. Diana Rodin and Sharon Silow-Carroll presented effective strategies for improving postpartum visit attendance among Medicaid participants. At the same time, Regina Troxell shared her unique perspective on navigating the $4^{\text {th }}$ Trimester as a Child Neurology trainee and the shortcomings of current medical education regarding providing compassionate family medical leave.

\section{Day Two: Medical Care:}

The second day started with an amazing review of the latest and most effective approaches to caring for opioid-exposed newborns by Susan Hwang, MD, PhD. A living legend then followed her in the field of midwifery, Dr. Ginger Breedlove, CNM, PhD, who gave one of the most thought-provoking and eye-opening talks identifying gaps in preparedness for parenting by weaving together stories, experiences, research, and observations from her own vast clinical experience, as well as her personal experiences as a mother and grandmother. She was followed by none other than
Sue Hall, neonatologist and a cornerstone of NPA, who not only gave a stirring presentation focused on trauma-informed care in the setting of giving birth amid Covid-19, she did so at the last minute when a speaker was unable to present. Finally, Noelle Ciara, DSW, LCSW, expertly tied together many of the themes for the day as she described a novel, attachment-based practice model she helped develop and now manages that supports providers working with mothers and infants impacted by opioid use disorders. The second day's breakout sessions provided insight into

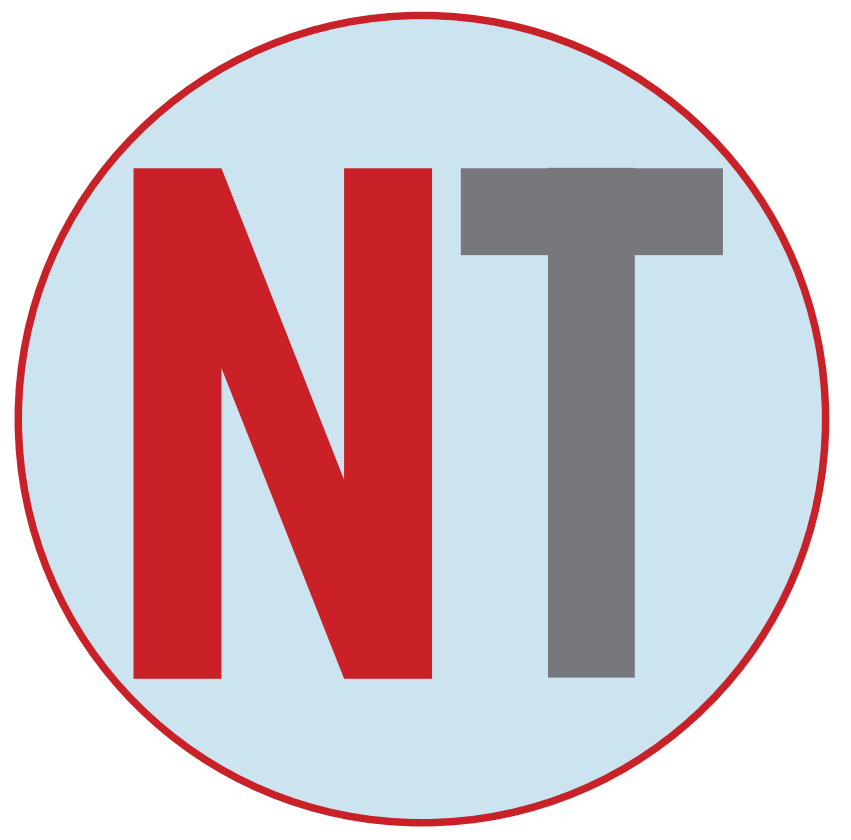




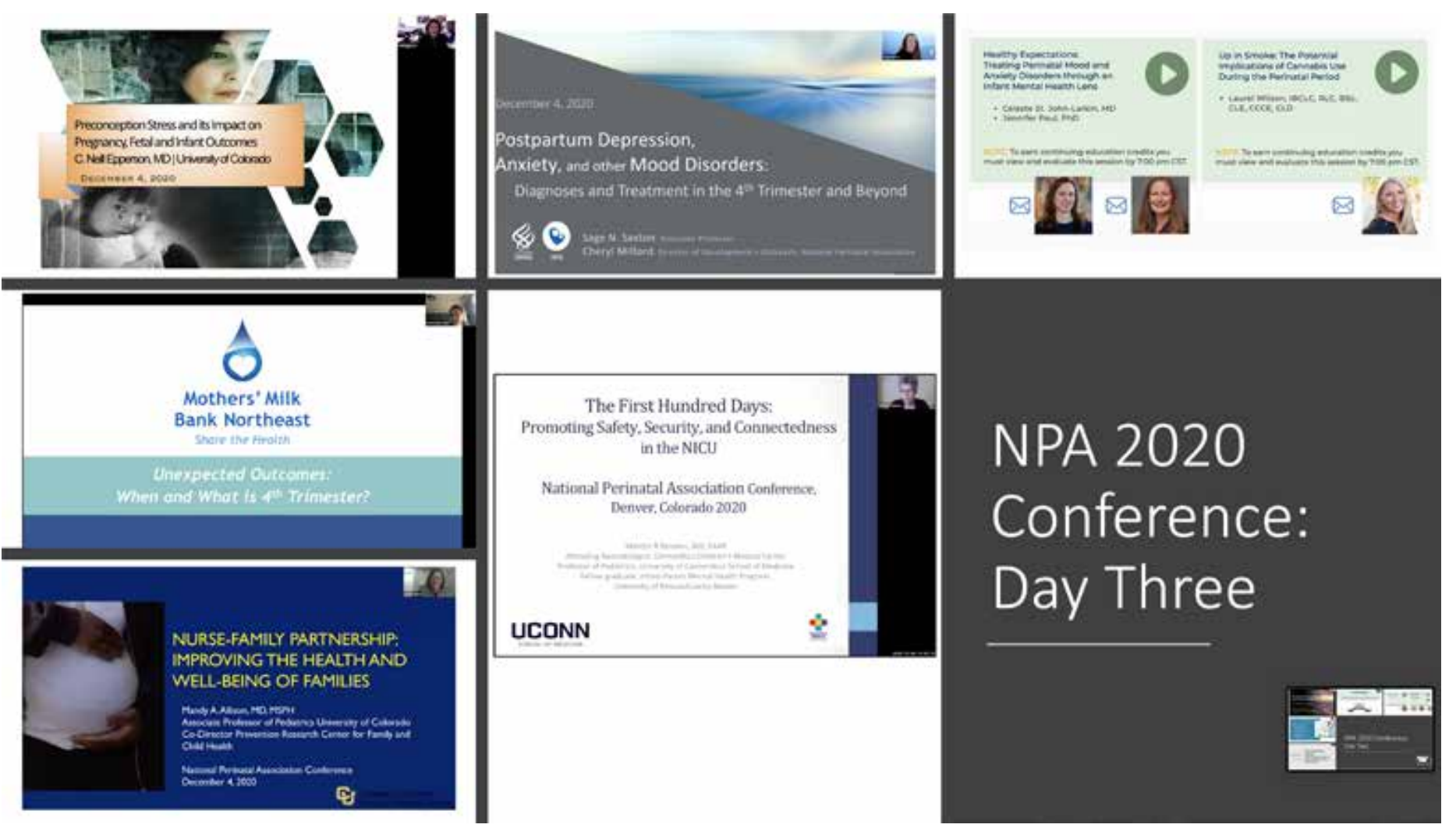

specific resources being developed by different working groups within NPA. Dr. Vincent Smith discussed NPA's ongoing initiative to develop comprehensive, evidence-based discharge and transition resources for NICU families, while a trio of NICU psychologists, Drs. Shelly Steinwurtzel, Allison Dempsey, and Sage Saxton provided updates on the myriad of projects spearheaded by NPA's Maternal Mental Health Group and the National Network of NICU Psychologists.

\section{Day Three: Mental Health:}

The meeting culminated with five incredible presentations that looked at mental health in the $4^{\text {th }}$ Trimester from five unique perspectives. Dr. Neill Epperson began the day with a deep, analytical journey into the genetic, neuronal, and biologic impact of maternal childhood adversity on pregnancy, fetal, and infant outcomes. Dr. Naomi Bar-Yam then took attendees to the other end of the analytical spectrum by providing epidemiologic and biomedical data on unexpected pregnancy outcomes to provide greater context when defining the $4^{\text {th }}$ Trimester at a societal level. Dr. Mandy Allison then presented specific strategies for confronting disparities in the $4^{\text {th }}$ Trimester and confronting socioeconomic gaps through nurse-family partnerships to improve the health and wellbeing of families in her region. We then heard from yet another living legend, Dr. Marilyn Sanders, who emphasized the deep-rooted themes of our conference by describing the importance of the first one hundred days of newborn life and how even in a setting as potentially chaotic as the NICU, there were proven strategies to promote safety, security, and connectedness between parents and their newborn. And finally, NPA's own Sage Saxton brought together our entire conference with a thorough, powerful, and empathetic talk on diagnosing and treating postpartum depression, anxiety, and mood disorders. Rounding out the final day were two informative breakout sessions. The first was from Celeste
St. John-Larkin, MD and Jennifer Paul, PhD, discussing perinatal mood disorders from the lens of infant mental health, and the second was by Laurel Wilson, IBCLC, who provided an updated, contemporary view of cannabis use and its potential implication during the perinatal period.

\section{Looking ahead to brighter days:}

Our 2020 conference was a testament to NPA's mission to serve as a national leader in promoting evidence-based advances in perinatal and postpartum care and elevating the voices of the most vulnerable parents and families so that all newborns and their parents are given the dignity and protection they deserve during the $4^{\text {th }}$ Trimester. The New Year brings with it the promise of a widespread Covid vaccine, amplification of solutions to health inequity and racial disparities, several state and federal bills supporting mothers and infants in the postpartum period, and further understanding of perinatal mental health and substance use disorders. With great hope, determination, and a newfound respect for the ability to convene in the absence of a physical convention, we are already planning for our 2021 conference that is scheduled to take place December $1^{\text {st }}-3$ rd. Whether it will be in-person in Denver, completely virtual, or a hybrid convention, we are confident it will provide the quality, passion, and multidisciplinary appeal that has become the hallmark of the National Perinatal Association.

Disclosure: The National Perinatal Association www.nationalperinatal.org is a 501c3 organization that provides education and advocacy around issues affecting the health of mothers, babies, and families.

NT 

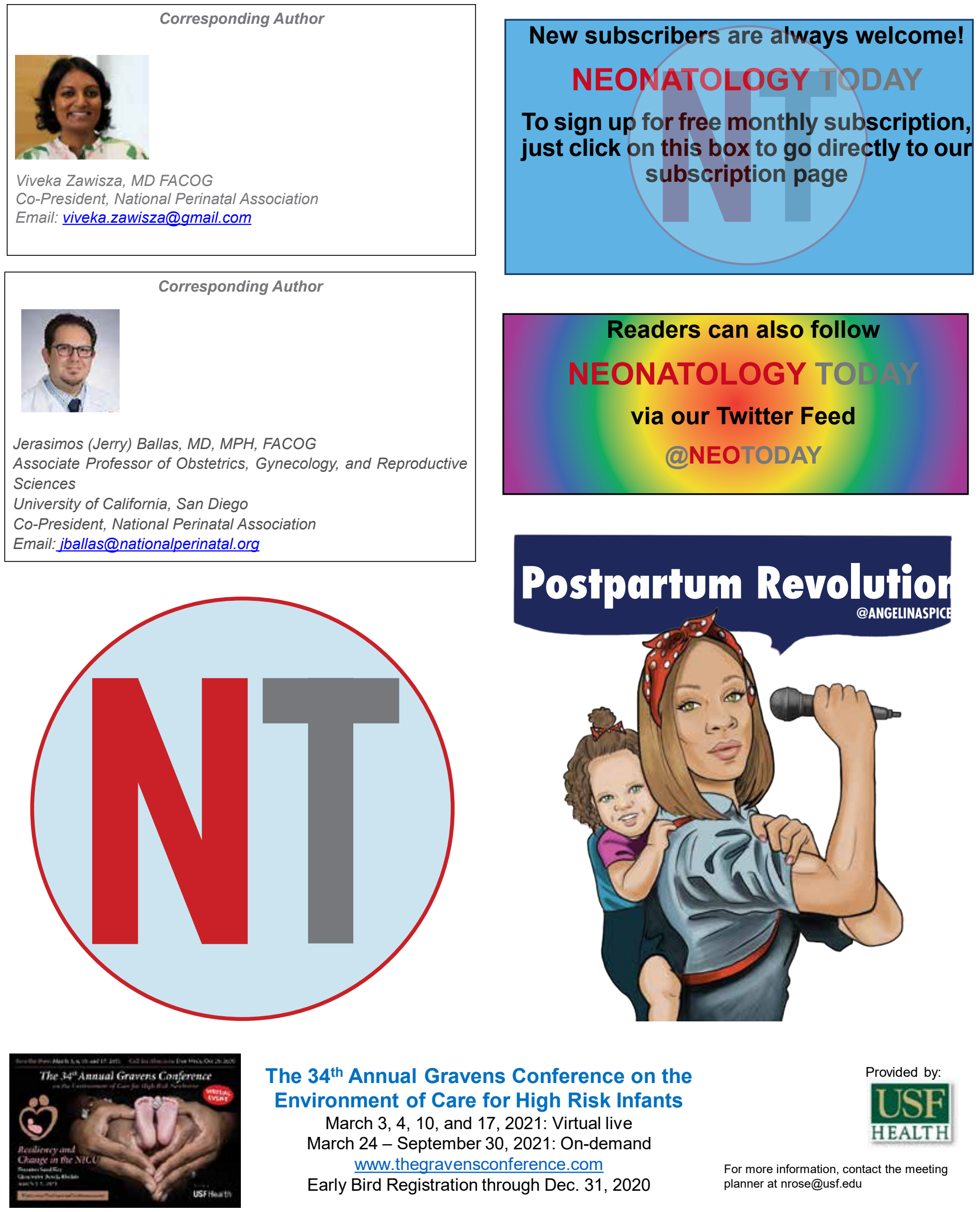

The 34th Annual Gravens Conference on the

Provided by: Environment of Care for High Risk Infants March 3, 4, 10, and 17, 2021: Virtual live March 24 - September 30, 2021: On-demand www.thegravensconference.com

Early Bird Registration through Dec. 31, 2020 